\title{
Aspect, time, and associative relations in Australian languages
}

\author{
William McGregor \\ Institut for Lingvistik, Aarhus Universitet, Danmark
}

Dieser Beitrag wendet sich gegen die starke Version der lokalistischen Hypothese, nach der temporale Kategorien in der Grammatik immer ihren Ursprung in räumlichen Kategorien haben und die Verbindungen zwischen ihnen metaphorischen Charakters sind. Es wird gezeigt, dass in einigen Aboriginalsprachen die komitativen Marker - denen räumliche Bedeutungen in der Kernsemantik fehlen und die im Allgemeinen keine historischen Verbindungen mit räumlichen Morphemen aufweisen - in die verbale Domäne eingedrungen sind, wo sie Tempus- und Aspektkategorien markieren. Es besteht Grund anzunehmen, dass sie auch als diachronische Quelle der Verbalmarkierungen temporaler Kategorien gedient haben. Es wird eine nicht-metaphorische Motivation für diese Bedeutungserweiterung und Grammatikalisierung vorgeschlagen, und zwar über eine komplexe Satzkonstruktion, in der zwei Teilsätze durch eine komitative oder assoziative Relation verbunden sind. Formal ist hier ein Prozess der syntagmatischen Generalisierung beteiligt; semantisch gesehen liegt Abstraktion vor, nicht Metapher.

\section{INTRODUCTION ${ }^{1}$}

Spatial morphemes represent a widely acknowledged source for temporal markers. Numerous languages use markers of spatial location such as at and be at in the expression of progressive aspect; indeed, such a source has been proposed for the English progressive be verb-ing, namely in an earlier expression involving a linking on that reduced to $a$ - and was ultimately lost (Bybee/Dahl 1989: 79). Such usages have often been interpreted as illustrating metaphoric extension from the spatial domain to the temporal domain, and thus that the temporal relation is construed as though it was a spatial relation.

The localist hypothesis holds that spatial grammar - the grammatical resources of a language deployed in the expression of spatial relations - forms the foundation of all or many (depending on how extreme a version is adopted) grammatical categories, including temporal ones such as tense and aspect. This hypothesis has been construed by many as illustrating deployment of spatial metaphor, and that this has a cognitive basis. Some consider this to be relevant to the synchronic state of a language or languages; examples are Lyons (1968), Anderson (1971, 1973), Jackendoff $(1990,1996)$, and Heine (1997a). Some interpret it in diachronic terms: that is to say, 
the grammatical categories deployed in expression of time derive historically from grammatical categories originally used exclusively for the expression of spatial relations. Many working in grammaticalisation theory adopt the latter view, not necessarily to the exclusion of the former; for example, Heine et al. (1991) and Heine (1997b) - though Heine explicitly argues that localism is only one of a number of metaphorical process involved.

For many years I have had reservations about the story as just outlined. Five considerations, not all independent, in particular I have been sceptical about.

- Universality: how universal is localism?

- Primality: how do we know that one of the semantic domains is the basic one, the other the extended or derived one?

- Attribution: what is the role of grammatical relations and constructions? These disappear from the picture presented in the localist and grammaticalisation literature. Only morphemes and morpheme semantics are taken into account; structure has no significant place.

- Metaphor: is metaphor really the mechanism involved, or the only mechanism involved?

- Cognition: do the grammatical facts elucidated really tell us anything about cognitive processes?

In this paper I discuss a grammatical phenomenon that encapsulates these misgivings. ${ }^{2}$ The phenomenon, which I have been aware of for many years but not scrutinised closely until now, seems to be little known outside of Australian linguistics; it concerns a morpheme that is used as a comitative marker on nouns but a marker of temporal relations on verbs.

\section{Major SENSES OF COMItATIVE MARKERS}

Perhaps the majority of Australian Aboriginal languages have a bound morpheme that typically attaches to the end of a nominal and has a meaning something like 'with' or 'having'. Sometimes it is described as a derivational morpheme, sometimes a postposition or case-marking suffix. In reality it often serves both functions in many languages - at least the most productive of the markers generally do. I will refer to such morphemes as comitatives, abbreviated COMs. ${ }^{3}$ This COM morpheme typically exists alongside a locative morpheme which conveys a more concrete spatial or temporal sense.

Figure 1 gives a rough indication of the range of meanings covered by COM markers in Australian languages; only a part of the range is likely to be covered in any language. See further Saulwick (1996), which provides a good typological overview of the forms and functions of COMs in Australian languages. What is indicated in this figure are the concrete contextual senses and uses of COM morphemes in particular examples, not their inherent meaning, which is (I would argue) a purely abstract associative relationship. Thus the locational sense of (1) - the natural interpretation that the man is located on the blanket - is engendered by the linguistic context. It is not actually 
encoded, and the man could equally have the blanket rolled up in a swag beside him. ${ }^{4}$

1) kinya wababkurru-barri yininy

this blanket-COM he:sat

Nyikina, 'He sat with a blanket.' (Stokes 1982: 105)

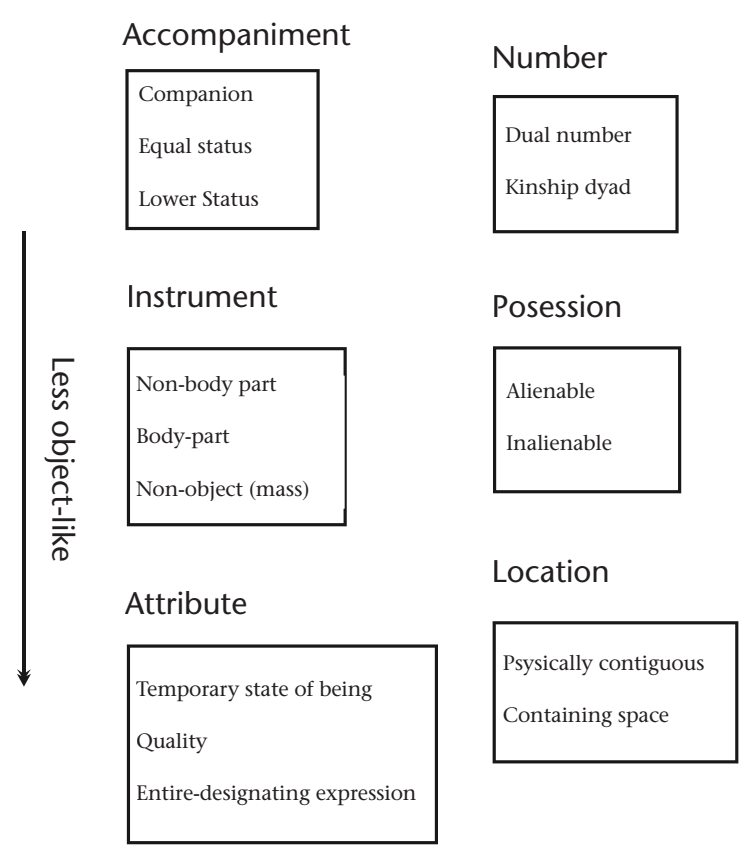

Fig. 1: Common senses of comitatives.

Before getting down to business, it is important to counter one possible line of objection from an adherent of localism, and to reiterate that the COM morphemes do n o t encode spatial relations. Rather, they mark abstract relations of association between entities, that one entity accompanies or is associated with another. They may be spatially contiguous, but this is inessential, and COM morphemes do not themselves actually specify or encode a spatial relation. No significant linguistic facts support the supposition that COMs are fundamentally spatial in their inherent semantics, their core meanings, and we do not find genuine COM morphemes marking spatial relations. (Locative morphemes sometimes also mark certain types of associative relation, but this does not make them COMs.) The fact that spatial contiguity is present in the prototypical case is irrelevant; so also is temporal simultaneity, and nothing justifies considering either as the more fundamental or basic.

Moreover, cognates suggest that COM markers frequently have origins in quantifying elements, rather than spatial terms. Thus the following are amongst the most widespread COM markers (see also Dixon 2002: 170), where TH indicates a laminodental stop in languages where there is a phonemic contrast between lamino-dentals and lamino-palatals, and a palatal stop in languages that do not make this contrast: 


$$
\begin{aligned}
& \text {-THirri - -THirr -THi - -yi } \\
& \text {-THarri -THa } \\
& \text {-garra }(y) \sim-\text { garri -gi } \\
& \text {-barri - -bayi -ba -wa }
\end{aligned}
$$

It is beyond the scope of the present paper to provide motivated historical reconstructions of the COM morpheme in any language or group of languages; I content myself with observing the formal similarity of the above forms with the two most widespread forms for 'two', guTHarra and pula. Locative morphemes exhibit a wide variety of shapes across the continent, though they are rarely bisyllabic and show little resemblance to the above forms; within the Pama-Nyungan family the following are amongst the most common forms: ${ }^{5}$

$$
-d a \sim-l a \sim-n g g a
$$

Comitatives sometimes encroach on temporal and modal domains, as Saulwick (1996: 73-82) documents. In a number of languages it can be attached to a nominal (or other word) specifying a time, or used in a temporal sense, as in (2) and (3).

2) bud yinkanada bayin-ngany arise he:used:to:carry night-COM Nyikina, 'He always used to get up very early in the morning.' (Stokes 1982: 592)

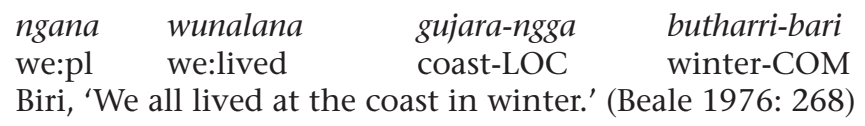

\section{USES OF COMITATIVE MORPHEMES FOR MARKING TENSE, MOOD AND ASPECT}

In some languages the COM morpheme, normally a nominal affix or enclitic, encroaches on the verbal domain, and appears as a verbal affix — or, alternatively put, there is a verbal morpheme sharing identical forms (including allomorphy) with the nominal COM affix. In this environment the COM morpheme is used to indicate, among other things, applicative constructions, subordinate clauses, reflexive/reciprocal voice, and temporal relations. In the latter case, the COM serves as a marker of tense, mood, or aspect. We will begin with aspect (3.1), and then discuss tense and mood, which as usual are difficult to separate (3.2). Finally (3.3) we mention some uncertain or questionable cases.

\subsection{Aspect MARKING}

Saulwick (1996: 80) finds just two languages, Arrernte and Walmajarri, that show evidence of a COM expressing aspectual meaning. In Arrernte the situation can be schematised as follows: 
NP-DAT-COM

V-PURP-COM spatial — up to a place: e.g. 'go as far as the creek' temporal - up to a time, up until a condition specified in a secondary predicate: 'I went to school until I was a young woman'

temporal - event described by main clause went on until the event described by $\mathrm{V}$, as in (4).

4)

re artne-pe-kwete-artne-ke m-ikwe petyalpe-tyeke-kerte

3sgNOM cry-FREQ-still-cry-PC mother-3sgPOS return-PURP-COM

Arrernte, 'He kept on crying until his mother returned.' (Wilkins 1989: 197)

In Walmajarri by contrast, the COM can be attached to a UV in what appears to be a non-finite clause to indicate that the event was completed when the main finite clause event occurred:

5)

$$
\begin{array}{lll}
\text { tikirr-jarti } & p a & \text { wulyu-tjarrin-jala } \\
\text { return-COM } & \mathrm{CA} & \text { well-become-then }
\end{array}
$$

Walmajarri, 'When he returned he got well.' (Hudson 1976: 205)

In both Arrernte and Walmajarri the COM marked verb indicates a telic event that is temporally located at the occurrence of another event - either at the latter's beginning (as in Walmajarri) or at its termination (as in Arrernte). These uses are hardly surprising to speakers of English, since they admit translations involving have - 'he kept crying until his mother had arrived' and 'having returned he got well'; the perfect indicates the relevance of the arrival or returning event to the other event.

In fact, other Australian languages employ COM markers in the expression of aspectual meaning. Perhaps surprisingly for the speaker of a SAE language, in a number of languages from the north-west of the continent it indicates a progressive (or continuous) aspect, sometimes iterative.

\subsubsection{Progressive aspect}

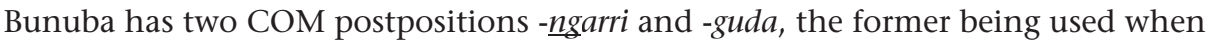
the entities have unequal status, the latter when they are of equal status (Rumsey 2000: 61-63, Knight in preparation: 122). - Ngarri is also used on inflecting verbs (IVs) where it expresses an aspectual meaning, ${ }^{6}$ indicating that the event is viewed as one that is spread out over time, either extending over a period of time, or that it occurred regularly during a period of time as a matter of course - roughly a habitual or characteristic sense. ${ }^{7}$ This is sufficiently close to a progressive sense to warrant the use of that term (Bybee/Dahl 1989: 55), and I gloss it accordingly in the examples; Rumsey (2000: 97), however, refers to it as a "continuative". Examples illustrating its use are:

6) mamu-yawu

corpse-ALL 
Bunuba, 'Banggarri is what they call it in the Aboriginal language.'

8) mingali-ingga gay-gay-tha'yirra-ngarri

hand-ERG cut-cut-REP'3sg<1EXC/PA/RA-PROG

Bunuba, 'We used to cut [fence posts] by hand.'

The Bunuba progressive does not seem to be used relationally, that is, to situate another event within its temporal duration, as in English expressions such as As he was coming to the corpse, they attacked him. However, as illustrated by example (9), the PROG in Bunuba can have a backgrounding function.
ban.ga ra-nggarri-biyirrantha/
wiyi-u/
ngangga/ win-da-ntha
return $3 \mathrm{sg}<3 \mathrm{sg} / \mathrm{RA}-\mathrm{PROG}-3 \mathrm{duOBL}$ woman-DAT give $\quad 3 \mathrm{pl}<3 \mathrm{sg}$-YHA-DU
Bunuba, 'He'd take it back for the two women and give them (the meat).' (Knight in preparation: 325 )

Many Worrorran languages also have a COM postposition -ngarri - in some languages it has lost semantic specificity somewhat and become an associative marker, indicating a habitual association - that also has verbal uses. In Ngarinyin, attached to an IV it is serves as a generalised subordinate clause marker, marking temporal, locational, and relative clauses. In many other languages it has a range of temporal uses, some of which appear to be aspectual (unfortunately, the meagre information available for a number of languages does not permit definite conclusions to be drawn, as we will soon see). This is the case for the putative cognate -ngay in Gunun/Kwini, which has apparently weakened semantically to mark characteristic associations of entities (McGregor 1993: 25, Capell/Coate 1984: 30). One of its verbal uses is as a progressive, indicating either a single event that went on for some time as in (10), or that events of the type were habitually performed as in (11) (McGregor 1993: 47).

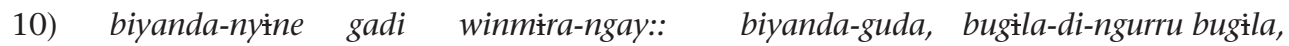
child-COM run she:took:it-PROG child-COM that-INT-INDEF that Gunun/Kwini, 'It [the kangaroo] was running along with the child in its pouch.' (McGregor 1993: 47)

11) mee-we wurrmira-ngay, malgarrawa birririj mudne, food-COM they:got:it-PROG smoke make:smoke they:acted:on:it Gunun/Kwini, 'They used to go for food, and make smoke.' (McGregor 1993: 47)

Aside from serving a backgrounding function, Gunun/Kwini -ngay also marks generalised subordinate clauses, like Ngarinyin -ngarri.

Far to the south-west, in Unggumi and Yawijibaya, it seems that -ngarri is also used as a progressive, and may be taking over some of the domain covered by -(y)irri, etymologically the progressive suffix in the languages of the subgroup (Capell and Coate 1984: 207); see also below 4.1. This seems to be especially the case in referring to currently ongoing events (cf. Saulwick 1996: 75): 
majarawi jarrngali gubanu-ngarri

children play they:do-COM

Unggumi, 'The children are playing.' (Capell/Coate 1984: 207)

13) manjum woo muwane-ngarri

wind blow it:does-COM

Yawijibaya, 'The wind is blowing.'

\subsubsection{Iterative ASPECT}

In the previous section we saw the COM attached as a suffix or enclitic to the end of IVs; COM affixes are sometimes found attached to UVs, again expressing aspectual meaning. One of the Wunambal comitative markers (not the most productive one), -wa or -we (Capell/Coate 1984: 149), is used in this way as an iterative marker: bara-wa (talk-IT) 'talk a lot' (Vászolyi 1976: 639), jawirr-wa (rub-IT) 'rub repeatedly' and dajud-ba (teach-IT) 'teach repeatedly' (the initial glide hardens following an occlusive). ${ }^{8}$

\subsection{COMitATIVES AS TENSE AND/OR MOOD MARKERS}

Saulwick (1996: 75-80) identifies a tense and/or mood sense of the COM in just a few languages. Two, Kayardild and Yukulta, belong to the Tangkic family (North Queensland) and exhibit the phenomenon of "modal case marking", in which case marking has a modal function. In Kayardild modal case markers appear on all non-subject nominals, and also on the verb as well. ${ }^{9}$ In the following example the morphemes glossed FUT are etymologically and possibly synchronically identifiable with the erstwhile COM morpheme, and represent modal uses of that morpheme.

\begin{tabular}{|c|c|c|c|}
\hline $\begin{array}{l}\text { nyingka } \\
\text { you/NOM }\end{array}$ & $\begin{array}{l}\text { kurri-nang. ku } \\
\text { see-NEG/FUT }\end{array}$ & $\begin{array}{l}\text { niwan-ju } \\
\text { 3sg-FUT }\end{array}$ & $\begin{array}{l}\text { malmbi-wu } \\
\text { tomorrow-FU }\end{array}$ \\
\hline
\end{tabular}

Kayardild also has a verbal potential suffix $-T H u(r u)$ that is apparently historically related to the COM and that forms a construction in association with NPs marked by the modal COM. This has a range of meanings: expectation/futurity, prescription, ability, repeated actions in the past, jussives, and purposives. Examples are (15) and (16).

$\begin{array}{ll}\text { niya } & \text { bukawa-th } \\ \text { he } & \text { die-POT }\end{array}$
mungkiji-wu own-COM

$$
\begin{aligned}
& \text { dulk-u } \\
& \text { country-COM }
\end{aligned}
$$

Kayardild, 'He will die in his own country.'

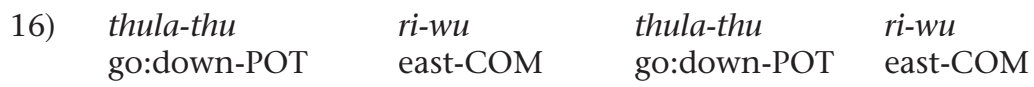

Kayardild, '(They would) go down to the east, go down to the east.' (Evans 1985: 581)

In the Nyulnyulan language Big Nyikina the comitative postposition -ngany can be attached to an IV with a similar temporal or modal sense, as in (17). Notice that both verbs are in future tense, locating the events in the future with respect to speech time; $\mathrm{COM}$ on the second verb indicates that that event is situated in the future with respect to the first, and/or is an intention of the speaker. 


$\begin{array}{llcl}\text { ngangama } & \text { marduwarra-ngana } & \text { kung } & \text { ngani-ngany } \\ \text { I:will:go } & \text { river-ALL } & \text { drink } & \text { I:will:say-COM } \\ \text { Big Nyikina, 'I'm going to the river to drink.' (Stokes } & 1982: \text { 318) }\end{array}$

The Big Nyikina comitative postposition -ngany is a reflex of proto-Nyulnyulan *-ngany COM (McGregor 1997, 1998a, Stokes/McGregor forthcoming); a reflex of this postposition can also be found in most other modern Nyulnyulan languages. However, it has specialised as an instrumental marker in almost all of them, leaving just a few remnants of its earlier more general comitative sense. It is universally used on IVs, where it is used as an applicative (see e.g. McGregor 1998a), and/or with temporal/ modal meaning similar to (17). Warrwa examples (18)-(20) are illustrative.

$\begin{array}{lllll}\text { jarrbard nangkan kaliyal warli jina nungkarli-ngany/ } \\ \text { lift:up he:carries finish meat his } & \text { he:will:eat-COM } \\ \text { Warrwa, 'He is lifting it up so he can eat the meat.' } & \end{array}$

$\begin{array}{lllll}\text { kinya-na warli ngaalu-nma } & \text { kanyjirr } & \text { ngiran-jina } & \text { kalb-ankaw/ } \\ \text { this-ERG meat } & \text { white:Cockatoo-ERG } & \text { look } & \text { it:is-3sgOBL } & \text { up-ABL } \\ \text { nungkarwa-ngany } & \text { kinyal } & \text { bardkurru } & \text { warli/ } & \\ \text { he:will:follow:it-COM this } & \text { kangaroo meat } & \\ \text { Warrwa, 'The white cockatoo was looking at him from on top, intending to } \\ \text { follow him.' }\end{array}$

$\begin{array}{lllll}\text { mijala } & \text { nganganiny } & \text { kinya-n } & \text { gidii } & \text { kuna-ngany } \\ \text { sit } & \text { I:stayed } & \text { this-LOC } & \text { sun } & \text { it:will:do-COM }\end{array}$

Warrwa, 'I sat there waiting for the sun to rise.'

An IV in Warrwa marked by -ngany COM can also be used in independent clauses, where it conveys an imminent sense, as the following pair of examples show:

21) kinya wamba wila-yinu wali nungkarli-ngany jakiny-kudany this man water-ABL meat he:will:eat-COM meat:taboo-COM 'This man is about to (intends to) only eat fish, being under a meat taboo.'

22) bany nungkama-ngany

shoot he:will:put-COM

'Someone's about to shoot him.'

Putting all such examples in Warrwa together, it is clear that the verbal construction marked by -ngany denotes an event projected for the near future, usually either by an interactant in the speech situation, or a participant (usually, but not necessarily the Actor) in the referent event(s). Intentionality to perform it need not be present, though it often is. The clause is typically linked to another finite clause specifying an enabling event; however, independent use also occurs. Similar examples are attested in Nyulnyul, where the marker shows up as -ang in both nominal and verbal environments, as shown by example (23). 

Nyulnyul, 'He gave him a needle in the arm to make him better.'

One example in the Worrorran language Wolyamidi illustrates a similar use of the comitative marker -gude; this is (24). (It must however be qualified with the reader that this is the only example available, and the language has not been investigated in depth.)

24) den ngarra:gude

light:fire I:do-COM

Wolyamidi, 'I am going to, am already in the process of making a fire.' (Capell/ Coate 1984: 159)

In Yukulta, a Tangkic language related to Kayardild, the COM has a variety of different allomorphs including -wurlu $\sim$-ngkurlu -kurlu -tjurlu. Attached to a verb it has similar senses to the Nyulnyulan verbal COM, signifying desiderative mood and imminent events, as in (25).
rtiija-thayi
makath-urlu
sit/INDIC-I/FUT
rest/INDIC-COM

Yukulta, 'I'll sit down and have a rest.' (Keen 1983: 247)

\subsection{UNCERTAIN CASES}

Warungu example (26) apparently illustrates a future sense of the COM morpheme when attached to a verb. (The initial lateral of the verbal comitative is the conjugation marker for the verb class.)
ngaygu gayana-nggu
gambi- $\varnothing$
manja-lji
I-GEN
father-ERG
clothes-ABS
send-VCOM
Warungu, 'My father will send clothes.' (Tsunoda 1976: 223)

However, it seems that this is the only such example. Furthermore, according to Tsunoda (1976: 223) -lji also expresses "stative aspect" — indicating a state, habit, or inclination - for four intransitive verbs, jagu 'feel sorry', ngurga 'be embarrassed', wanba 'fear', and gubi 'whistle'.

Capell/Coate (1984: 200) aver that -ngarri can be attached to the IV of an independent clause in indicative mood in many southern Worrorran languages, including Ngarinyin, Winjarrumi, Yawijibaya, Unggarrangu, Umiida, and Unggumi. They suggest that it serves a type of modal function of assertiveness, adding definiteness and emphasis to the assertion, indicating that the speaker vouches for the proposition. The examples they give are reminiscent of what I refer to as exclamative mood in Gooniyandi. Two of their examples will suffice: 
27) dewad bungaawun-ngarri

break I:hit:it-COM

Yawijibaya, 'I am breaking it.' (Capell/Coate 1984: 200)

28) yinggerri gee ngunbuna-ngarri

he call:out he:hit:you-COM

Unggumi, 'He was calling out to you.' (Capell/Coate 1984: 200)

It is rather difficult to reconcile the proposed emphatic sense of the COM with the other senses that the morpheme apparently displays when attached to IVs - in particular subordination and progressive aspect — which are suggestive of a demotion or backgrounding of the event. It does seem, however, that the COM affix exhibits aspectual and/or modal uses.

\section{IMPLICATIONS}

Section 3 presented a few case studies that showed formally identical markers on both nominal and verbals - comitatives in the former case, and tense, mood or aspect markers in the second. These similarities could be purely accidental. However a number of considerations suggest to the contrary, that there exists a motivated link between nominal comitative markers and verbal aspect and/or tense markers. First, in some instances the same allomorphs were found in both environments, with the same conditioning factors. Second, in some cases we were dealing with bisyllabic forms, decreasing the likelihood of accidental identity. Third, in some cases the modern reflex of a nominal comitative morpheme of a proto-language bore indication of phonological changes; so also did the corresponding verbal marker. At least in the Nyulnyul case, this change is not consistent throughout the lexicon, but is restricted to these morphological environments. Fourth, the similarities are not restricted to a single language. These observations at least suggest it may be worthwhile enquiring into possible motivations for the formal similarities, and the possibility that nominal comitatives serve as sources of tense, mood and/or aspect morphemes in some modern languages — or the reverse! We deal with these in reverse order in the remainder of this section.

\subsection{Possible ReFLEXES of COM MARKERS IN VERB MORPHOLOGy}

A preliminary investigation was undertaken into tense and aspect markers in a small selection of Australian languages, including around thirty additional to those already mentioned (a number of which we will be returning to). Perhaps the most significant problem in this investigation is that the forms we are dealing with tend to be short: COM markers are typically monosyllabic or bisyllabic, while many tense and aspect markers are even more reduced in form, often monosyllabic or smaller. And they tend to show irregularities according to conjugation class and the like. In the absence of a careful historical-comparative investigation, we cannot reasonably conclude anything from the fact that one the present tense allomorph in Atampaya is -ma, which is strikingly similar to one of the comitative markers, -iima (Crowley 1983: 346). On the other hand, a verbal morpheme could well reflect a previous COM affix that has gone out of use, or been reanalysed. We might then expand our search to include verbal 
affixes that show formal resemblances to widely distributed COM morphemes, or to COM morphemes in related languages. Again it is possible to find suggestive similarities such as that between the Gugu Yalanji inceptive marker -ja 'about to, begin to' (Yallop 1982: 108) and the widespread -THarri COM, a reflex of which may be COM in Kugu Nganhcara (Smith/Johnson 2000: 397).

Such similarities as these do not add to our case, and therefore we must look for more convincing examples, where controls are tighter. A number were uncovered in the investigation, further arguing against accidental similarity of forms. We begin with a few cases in which the nominal morpheme is not synchronically a comitative, but can plausibly derive historically from a comitative.

Ndjébbana has a bivalent suffix -(i)-ba -(V)-bba that Graham McKay glosses as EXTent (McKay 2000: 199). It attaches to a small set of three nominals to form plurals (in combination with prefixes). It also shows up as a NP conjunction, as in ngarráma-bba yídja (woman-EXT man) 'men and women' (it is unclear how general this usage is, whether it is restricted to the three nominals forming their plural with it). It occurs apparently more productively in combination with the locative prefix, in the form (ba)na-N-bba 'in/at the place where $\mathrm{N}$ is found'. These synchronic facts suggest that the morpheme may be the reflex of a once more productive COM morpheme (Ndjébbana no longer has a separate COM). This suggestion is perhaps further supported by the existence of derivational uses, which exhibit unclear and irregular semantic features. Furthermore, it is a plausible cognate of one of the widespread COM markers, -barri -warri (cf. the form -wa -ba in some Worrorran languages.)

The suffix shows two verbal uses. One is as what seems to be an aspect marker, with senses durative, habitual, and iterative, as in (29). The other is as a marker of a temporal subordinate clause, indicating an event simultaneous with or sequential to the main clause event, as in (30).

$\begin{array}{lll}\text { ngandjúddama... } & \text { barra-múyi-ba } & \text { barra-ngóddji-ba } \\ \text { bark:canoe } & \text { 3AUG-dead-EXT } & \text { 3AUG>3min-call-CTP-EXT }\end{array}$

Ndjébbana, 'It was what our ancestors used to call ngandjúddama (a bark canoe).' (McKay 2000: 199)

$$
\begin{array}{ll}
\text { nja-rra-baló-bba } & \text { njanbi-rri-bbándja-nga } \\
\text { 1AUG-RE-come:hither-EXT } & \text { 3AUG>1AUG-RE-put-R }
\end{array}
$$

Ndjébbana, 'When we arrived there they dropped us off.' (McKay 2000: 308)

The Ndjébbana suffix -(i)-ba -(V)-bba thus lends plausibility to our hypothesis: it seems reasonable to trace it back to an earlier nominal COM, and shows verbal uses as an aspect marker.

The Worrorran language Ngarinyin has an aspect marker glossed continuative (CONT) in Rumsey (1982: 75). It is a suffix that goes towards the end of an IV, in almost final position, and has allomorphic shapes -yirri -nyirri, the first following vowels, the second following consonants (which must be an apical nasal). There are a number of morphophonemic rules - peculiar to the CONT — affecting its realisation: the initial $y$ behaves in a different way to other $y$ morphophonemes in the language. We need not 
be concerned with these details here. The semantics of the morpheme is not discussed in detail in Rumsey (1982), but it seems from examples given that it is primarily used in reference to single events that extend over a stretch of time:

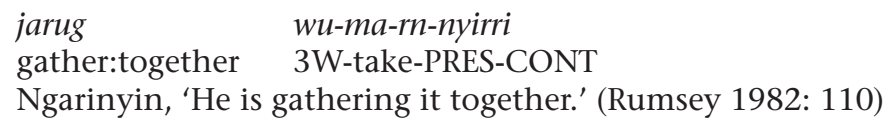

Interestingly, the Ngarinyin CONT is regularly used in negative imperatives - not just for negative continuing commands, 'don't continue to', but also for commands where the action has yet to begin, as in (32).

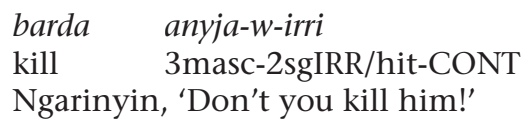

Rumsey (1982: 101) suggests that the sense is 'continue not to', rather than 'don't continue to' - that is, the aspect holds the negative in its scope, rather than the other way around. An alternative interpretation is that the CONT, at least in the context of telic events, is a type of progressive, picking out the period of build-up prior to the accomplishment, and that what is negated is that even this be entered. In other words, it might be (or derive from) a somewhat stronger negation than "do not do", viz "do not enter into the process of doing". This interpretation has the advantage that it is consistent with the fact that negation often has wider scope than aspect, which typically relates to the verb; it also suggests that the morpheme may be regarded as a progressive. Different scopes associated with the negator 'not' - narrow or wide - would then account for the different possible interpretations available, depending on verbal Aktionsart (and context).

The Ngarinyin CONT bears no resemblance to any of the COM postpositions or suffixes in the language. However, there is a dual number suffix for nouns that takes the shapes -yirri -rri -nyirri, the first two allomorphs following vowels and glides, the second elsewhere (Rumsey 1982: 59). There is also an almost identical dual affix that occurs in IVs in the order-class that immediately precedes the CONT, with allomorphs -rri (following vowels) -nyirri (elsewhere).

There is an obvious semantic connection between the notion of duality and comitative, and this is widely attested in "polysemies" of the comitative in Australian languages, and in the historical sources of dual or comitative markers (Saulwick 1996; see also Figure 1). Furthermore, plausible cognates of the dual affix in Ngarinyin can be found in one of the Nyulnyulan COM affixes - -nyirr (Nyulnyul, Jabirrjabirr, Nimanburru), -(i)nyarr (Bardi), and -nyarri (Warrwa). Even in the Worrorran family plausible cognates of the Ngarinyin dual can be found, including Wunambal and Forest River -yarri (Capell/Coate 1984: 155) and majerri 'two' in Kunin/Gwini, suggesting strongly that we can trace back to a form such as *-(n)yarri *jarri in proto-Worrorran. What was it? A comitative or a dual marker? Or a marker of augmented ${ }^{10}$ These questions can't be 
answered in this paper. Nevertheless, it is not implausible that the morphemes at issue bear some historical relation to the pan-Australian kujarra gujarra 'two' - cf. Dixon's reconstruction of proto-Australian 'two' as *guDHarra(n) (Dixon 1980: 323).

The Ngarinyin data is highly suggestive of a connection between the CONT morpheme and the dual morphemes (nominal and verbal). In fact, a CONT affix with almost exactly the same shape is found in most, if not all Worrorran languages, including languages from all three groups, though information is inadequate for many languages (Capell/Coate 1984: 207; Vászolyi 1976: 632-633). Worrorra itself has -(y)eerri CONT, though it lacks a cognate dual or COM morpheme (Clendon 2001: 154). This category seems to be used for events extending over a period of time, whether or not they actually fill that time period, as (33) and (34) illustrate; it is not, however, used for characteristic actions or general truths (Clendon 2001: 184). ${ }^{11}$

$\begin{array}{llll}\text { nye-ngurr-eerri } & \text { abeerla } & \text { maa, ke manja } \\ \text { 3sgFEM/go/PA-away-CONT } & \text { slow } & \text { CONT and } & \text { meet } \\ \text { ka-wee-ng-aarndu } & \text { inja } & \text { iwarnbarnngarri } & \\ \text { 3A/hit/PASS-PRES-DU } & \text { 3aDET } & \text { snake:species } & \end{array}$

Worrorra, 'She went along slowly until she met up with the king brown snake.' (Clendon 2001: 181)
jijaaya
Mr:Love
nguru k-err-kangurr-eerri
ka-rloo-rl-erri
$\begin{array}{ll}\text { Mr:Love hear 3a-1plEXC-carry-CONT } \\ k e, & \text { karra-ngarri, karnmanya }\end{array}$
3wREF high-ASSOC Kunmunya
'We used to listen to Mr. Love at Kunmunya when he talked about heaven.'
(Clendon 2001: 181)

Summarising, the CONT suffix of Worrorran languages may be plausibly traced back to an early comitative. This has been lost in many modern languages (attesting to its age), though a reflex remains in the Ngarinyin dual, as well as in a Nyulnyulan COM.

A similar case might be mounted for the pan-Worrorran iterative aspect suffix - $b a \sim-w a$ (Capell/Coate 1984: 209). This suffix attaches exclusively to UVs, and is illustrated by the following Ngarinyin example:

$\begin{array}{lll}\text { 35) } & \text { inggarr-ba } & \text { nyadumanga } \\ \text { aeroplane } & \text { pick:up-IT } & \text { it:took:us }\end{array}$

Ngarinyin, 'The aeroplane picked us up one by one.' (Rumsey 1982: 121)

In Worrorra, according to Clendon (2001: 391), although the cognate morpheme frequently shows an iterative sense, this is a result of the semantics of UV it is attached to, and it is essentially a marker of progressive aspect, as illustrated by:

36) $\begin{aligned} & \text { nyi-mnya-wa-na-ngurr-eerri } \\ & \text { descend-PROG }\end{aligned}$ 3fem-PROX-fall-PA-away-CONT
Worrorra, '(The sun) sank down slowly.' (Clendon 2001: 391)

Further afield, in Bunuba it appears to be a derivational affix, deriving an atelic UV from a telic one, and the derived form normally selects an atelic classifying IV (Rumsey 2000: 97), as in (37). 
Given the allomorphy represented by the initial glide-stop alternation, it seems not unreasonable to presume this widespread iterative to be cognate with the Wunambal iterative discussed in 3.1.2 above. Only in Wunambal, however, is there a corresponding COM marker on nominals, which might be taken as evidence against historical origins of the verbal aspect marker in a nominal COM. But aside from the fact that the form is identical with one of the recurrent COMs (which is admittedly weak evidence, given the size of the form at issue), there is some modern evidence suggestive of an origin in an earlier COM. In Ngarinyin, a formally identical morpheme (showing the same allomorphy) is found as a derivational morpheme deriving adverbials from nominals (Rumsey 1982: 126). Rumsey is doubtless correct in his evaluation that this identity of form is synchronically fortuitous, and that two separate morphemes would need to be identified in the modern language. However, I believe that a case can be made for relating the Ngarinyin adverbialiser to an earlier COM affix. Indeed, in Gooniyandi (closely related to Bunuba, but not known to the related to Worrorran languages) we find a morpheme -wa with a similar range of uses. I have suggested elsewhere (McGregor 1998b) that the Gooniyandi morpheme may share the same origins as the Wunambal $w a$ (etc.) in a very early COM. Perhaps this was the source of the iterative affix to UVs in many modern Worrorran languages, and the adverbialiser of Ngarinyin, these being the grammatically marginal remnants of the earlier comitative.

Turning now to Pama-Nyungan languages, in a number of Western Desert varieties — including Yankuntjatjara (Goddard 1985: 129) — we find the affix -kitja on both nominals and verbals with an inceptive or intentive meaning, indicating intention to be involved in an event or with an entity, 'about to'. Perhaps this can be analysed historically as a sequence *-ku DAT followed by *-tja, a reflex of -tjarra COM.12 At least the verbal usage would be comparable with one of the verbal uses of -ngany and its cognates in Nyulnyulan languages, as revealed in example (38).

\begin{tabular}{|c|c|c|}
\hline 38) & $\begin{array}{l}\text { wati } \\
\text { man }\end{array}$ & $\begin{array}{l}\text { paluru } \\
\text { DEF }\end{array}$ \\
\hline
\end{tabular}

Yankuntjatjara, 'The man went off wanting to shoot/roast meat.' (Goddard 1985: 158)

Common to many Western Desert varieties is also a suffix -payi that serves as (i) a derivational affix deriving nominals from verbs, and (ii) a marker of habitual action. Perhaps this can be traced back to an earlier comitative *-parri, via a not uncommon phonological process of yotocisation of the rhotic (we have already seen this process in the Worrorran language Gunun/Kwini).

Similarly in Gunya we find -bayi COM, alongside -barri in neighbouring and closely related Margany (Breen 1981: 312). Interestingly in both languages the potential mood marker involves the -bayi segment: -nybayinga. Semantically irrealis is not a far cry from the inceptive and intentive senses identified for Nyulnyulan languages. 
In Djabugay we find a similar formal correlation between -mbarra COM ('associated with') and the verbal irrealis marker $-(l / y$-) barra.

It is well known that Australian languages frequently use the nominal dative (sometimes purposive) suffix on verbs to express future time, purposes, or intentions. Here also we are dealing with very short forms, generally the monosyllable $-g u \sim-w u$. The future tense maker in some languages could at least as plausibly be traced back historically to a comitative. Wambaya, for instance, has $-b a \sim-w a$ FUT, which is reminiscent of one widespread form of the comitative. Semantically this is not implausible, given the attested inceptive usage of COM markers in various languages. Even more speculatively, in Bunuban languages we find a future tense prefix $b i-\sim w i-$ (Gooniyandi) and $b u-\sim w u$ (Bunuba). It is at least as reasonable to trace the FUT affixes in Wambaya, Gooniyandi, and Bunuba back to an earlier COM as to an earlier DAT - changes to the vowel quality can be accounted for at least as readily and convincingly as changes to the initial consonant of one allomorph. (This does not argue for a comitative origin for the future in these languages, only that such an origin is no less plausible than a dative origin.)

\subsection{Motivation}

What are referred to in the Bunuba and Ngarinyin grammars as continuous aspect fits with the characterisation of progressive aspect in Bybee/Dahl (1989: 55) — "indicating the situation is in progress at reference time". According to Bybee/Dahl (1989: 77) progressive grams:

- $\quad$ show a strong tendency to periphrastic rather than inflectional expression;

- often have obvious lexical sources;

- have as their most common source "locative expressions paraphraseable [sic] as 'to be located in or at an activity'".

Certainly our progressives were not expressed with affixes of the prototypical inflectional type; yet they could hardly be called periphrastic expressions either. Lexical sources for Bunuba -ngarri COM are not apparent, and must be quite distant for Ngarinyin -(y)irri. What seems abundantly clear is that their sources are non-locative. The progressives I have discussed in this paper form genuine counterexamples to the proposed universal locative sources proposed by Bybee/Dahl (1989: 79), and thus also against the universality of the localist hypothesis. The comitative and number sources do not lend themselves to locative interpretations along the lines suggested by these authors for postural verbs and the like. This is not to claim that there do not exist amongst Australian languages cases of the type Bybee/Dahl (1989) identify as predominant in the world's languages; rather, the point is that such "locatives" are not the only source for progressives.

Viable explanations have been proposed in the literature for the use of locative expressions in progressives (e.g. Anderson 1973, Traugott 1978, Bybee/Dahl 1989: 
81, Heine et al. 1991: 36). Can credible explanations also be devised for the use of comitatives? I believe so.

Just a few investigators have commented on similarities between nominal COM morphemes and verbal aspect markers, let alone attempted to account for them. In relation to Bunuba Rumsey (2000: 97) proposes: "There is perhaps some commonality of meaning between these two morphemes, insofar as both have as one of their uses a kind of characterising function." Thus Rumsey links the uses together via the characterising function apparent in the nominal use of the COM and in the habitual use of the verbal COM, which also serves to characterise the entity habitually engaged in the event. The 'ongoing' progressive sense would presumably be a subsequent development - compare the situation in Yankuntjatjara where the characterising function (habitual) is apparent but not the progressive.

In relation to the imminent sense associated with verbal COMs, similar explanations have been put forward by myself for Warrwa (McGregor 1997) and Dench/Evans (1988: 25-26) for Kayardild. According to their scenarios, main clause usage is a development from subordinate use via ellipsis of the main clause of a complex sentence that served as a type of intentional construction. The subordinate clause represents the subordinate event as an accompanying thought or intention of the actor as they perform the main clause act. The main clause could be ellipsed when it expressed predictable meanings, especially events that are ongoing in the speech situation; the erstwhile subordinate clause would thus typically represent an intention of the subject at the time of the speech event. With the passage of time, the intentional sense is lost leaving the purely temporal sense of imminence. Similar scenarios could perhaps be constructed to account for the development of irrealis and potential senses such as were encountered in a scattering of languages.

While both proposals have some plausibility, they suffer from being restricted to certain developmental pathways, and lack generality. I suggest that a modification to the second story can provide a general model that accounts for a wider range of phenomena. Let us suppose that the COM morpheme begins as a nominal affix expressing a comitative relation of the most concrete type, namely accompaniment - two persons are accompanying one another in the performance of an event - representing what Heine (1997b) refers to as the "companion schema". Over time weakening could occur in terms of both the types of things that are linked, and the relation of association involved. The linked things could progressively extend to accompanying animates, accompanying inanimates (and subsequently instruments), associated inanimates, and associated qualities (in many Australian languages there is no separate class of adjectives, and nominals can usually serve in both referring and attributing functions). This weakening process of semantic extension could be accompanied by a corresponding demotion in relative status of the accompanying entity: beginning with a situation in which the entities are equal status, and ending with a situation where the accompanying entity is of lower status.

At this point a further extension and generalisation is plausible, from an associated quality to an associated event. The associated event could be represented by a 
subordinate clause that establishes an associative relation either between two events, or between an entity and an event. On what basis could these associative relations have their foundation? At least two different bases are feasible. First, the associative relation could be prospective, the subordinate clause indicating a projected involvement of some individual in the main clause, or a projected consequence of the main event. Second, it might be a simultaneous association whereby one event happens in the same circumstances as another - at the same time or place - giving us when and where clauses, or involve one of the same participants, giving a relative interpretation. The first scenario would explain the Warrwa and Kayardild situation; the second would give rise to a generalised subordinate clause construction such as is found in Ngarinyin and many other Australian languages. Both involve time as the basis for the associative relation: there is no need to presume human intentionality, or spatial relations.

This scenario, I suggest, can be extended to the progressive aspect sense of the COM in languages such as Bunuba: it may have arisen historically via an intermediate process by which -ngarri COM served as a marker of a generalised subordinate clause type such as is found in Ngarinyin; this ultimately admitted independent usage via main clause ellipsis. Subsequently (for reasons that remain opaque) another morpheme, -nya, apparently replaced it as the marker of the generalised subordinate clause. An advantage of this grammaticalisation scenario is that it does not invoke an implausible parallelism like (40), whereby the COM is attached to the VP according to the model provided by its nominal uses. I consider this implausible because there is no evidence of nominalisation of the VP, or that the resulting construction is/was a verbless characterising (attributing) clause; the VP is consistently fully finite, with the usual range of participant types. My preferred alternative draws the parallelism shown in (41). Presuming the association is one of simultaneity, the associated event, being represented by a subordinate clause, would naturally be backgrounded with respect to the main clause; the association would be temporally based, and motivated by grounding. Thus the event would be naturally accorded temporal extent, and the progressive interpretation engendered. From this the habitual sense could develop. Unfortunately, I have no evidence for the occurrence of the intermediate step, the biclausal construction, in Bunuba.

40) $\mathrm{NP}_{1} \mathrm{NP}_{2}$-COM NP VP-COM

41) $\quad \mathrm{NP}_{1} \mathrm{NP}_{2}$-COM Clause $_{1}$ Clause $_{2}-\mathrm{COM}$
Entity ${ }_{1}$ is characterised by Entity ${ }_{2}$ Entity is characterised by Event

Entity $_{2}$ is associated with Entity ${ }_{1}$ Event $_{2}$ is associated with Event ${ }_{1}$ (perhaps via a participant in it)

According to the model I am proposing, verbal use of COM markers is a late development, and is probably never present from the beginning. Historical-comparative evidence suggests we reconstruct *-ngany COM as a bivalent marker in protoNyulnyulan (McGregor 1997); it is not possible as yet to push the clock back further to pre-proto-Nyulnyulan, and determine if this morpheme was always so promiscuous. Evidence from more recently acquired COM markers, however, suggests that they enter the language from the companion "prototype", the relation of equal-status accompaniment. None of the other COM markers have developed verbal uses. The 
situation appears similar in the Worrorran languages and Bunuba, where it is what appears to be only the oldest COM markers that are used on verbs. Strikingly, just one Worrorran language admits verbal use of a newer COM marker; this synchronic observation suggests a diachronic one, that nominal COM markers can over time acquire verbal uses. What of the Ngarinyin CONT suffix: how does it fit into this scenario? I submit that this represents the relic of an early COM marker, which once covered a wide semantic domain, including both nominal and verbal senses. This semantic domain was successively eaten into first by -ngarri COM and then -guda COM, each of which began life as markers of equal-status companions. As a result, what was left was a marker of dual number on NPs, dual number in the verb, and of CONT aspect on verbs. Over time, morphophonological processes occurred that resulted in its trifurcation, leading to the modern situation where there are three separate morphemes. Its relics were left in outlier roles of dual number and progressive aspect; it was protected so to speak in these specialisations, although over time newer COM markers assaulted even these domains. Thus the dual has subsequently been replaced in most other Worrorran languages by a new dual, leaving the only residue of this COM marker in the progressive aspect gram. A similar story applies to the old $-w a \sim-w e \sim-b a \mathrm{COM}$ of Worrorran; the only clear evidence of its status as a nominal COM marker is in two languages where it remains as a marginal marker of an unequal accompanying relation.

The grammaticalisation scenario I have proposed does not invoke metaphor. Rather, it is based on processes of generalisation of syntagmatic potential, and associated abstraction in the semantics, to the point that the COM becomes no more than a marker of a highly abstract relationship of association. When this point has been reached, the time is ripe for another morpheme to come along and take over at the concrete end of the range. One possible outcome is that the newcomer splits the semantic domain of earlier general morpheme, ultimately resulting in two or more morphemes, all of which display more concrete and less schematic senses.

To wind up my case, I outline some reasons why I consider metaphor to be irrelevant to the story. A purely circumstantial consideration is that the evidence we have adduced consistently points to the conclusion that extension to the verbal domain and temporal categories comes late, after broadening and generalisation of the range of nominal uses. If metaphor really were involved, why should there be evidence of extension to the various intermediate senses, and why should not the newest COM markers extend metaphorically? This raises the more significant question: wh at metaphor might be involved?

There is no evidence that spatial metaphor is relevant to the story of grammaticisation of nominal comitatives to verbal temporal category markers. Spatial senses remain consistently minor contextualisations of COM morphemes, and we have had no cause whatever to invoke them. Other linguists have argued against localism, pointing out that space is sometimes a derived category (e.g. Heine et al. 1991: 50). They propose six primary source domains for grammaticisation, which relate to six basic categories related in terms of abstraction: person, object, activity, space, time, and quality. These are shown in Figure 2, from Heine et al. (1991: 55). Heine et al. (1991) suggest that 


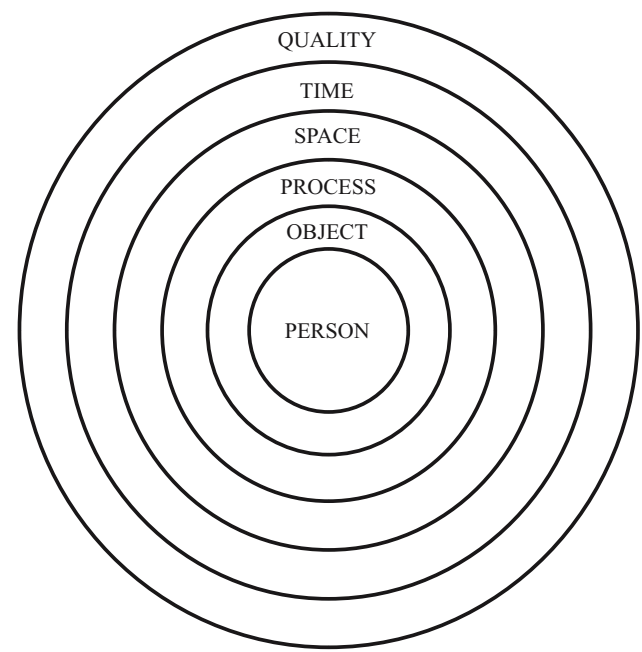

Figure 2: Heine et al's metaphorical categories (p. 55)

a category can serve as the metaphorical basis for conceptualising any less central category: the categories are linked by "a cognitive activity that we have referred to as metaphor" (Heine et al. 1991: 169). Space can, for instance, serve as a metaphorical vehicle for conceptualising time, but not the reverse. ${ }^{13}$

Nothing here obviously fits the bill for a metaphoric base for the temporal categories marked by COM morphemes or their reflexes. It seems completely spurious to invoke conceptual metaphors such as AN ONGOING EVENT IS A COMPANION for the Bunuba progressive, AN IMMINENT EVENT IS A COMPANION for the Warrwa imminent. Implausible as these doubtless seem, they are constructed on a metaphor proposed by Lakoff/ Johnson (1980: 134-135), and cited approvingly by Heine et al. (1991): AN INSTRUMENT IS A COMPANION, which allegedly underlies the use of with in both Bill went with John and Bill went with a car. Moreover, whatever cognitive support there might be for the latter metaphor, the linguistic support for it is no better than the linguistic support for the former metaphors - in each case it is no better than the observation that the same morpheme expresses the categories.

This brings us to my final observation against metaphor as it is frequently invoked in investigations of grammaticalisation: it tends to be based (as per the previous paragraph) purely on morphological form, to the exclusion of grammatical relations. Overt markers are imbued with the entire semantic burden. Such approaches run the risk of presuming implausible grammatical analyses. In the present circumstances, the analysis embodied in (40), namely that the same grammatical relation is involved in both uses of the COM - and a similar case can be made against the metaphor proposed by Lakoff/ Johnson (1980) to account for the instrumental use of with in English. Investigations of grammaticalisation must pay attention not only to the overt shape of morphemes, but equally to grammatical relations, constructions, and categories (see also McGregor 1994). Otherwise we run the risk of being misled by similarities that are merely skindeep, and draw unwarranted cognitive consequences from them. 


\section{CONCLUSION}

In this paper I have injected a temporal dimension into the investigation of time representation in grammar. I have discussed a not-widely-known source of progressive aspect markers, and shown that morphemes that mark abstract associative relations can be come to be used in the marking of temporal relations. I have made a story as to how this might occur, a story that does not focus entirely on the morphemes, but also takes some (still insufficient) notice of the grammatical relations they enter into. Marking of temporal relations emerges as a late development of COM markers. I have argued that there is no evidence that spatial relations are relevant to the story; indeed, they have a remarkably marginal place in the semantic range of comitative markers - to the extent that they are present, so also are temporal relations. There are no grounds for separating spatial relations from the four-dimensional space-time scheme as the most fundamental.

For a long time I have been of the opinion that metaphor is overused in many functionally oriented linguistic theories and grammaticalisation studies. I have proposed in this paper that a certain grammaticalisation domain is not driven by metaphor (cf. Heine et al. 1991: 48). Metaphor needs to be put in its place, and restricted if it is to be of any use. This goes for both language and cognition: in relation to language we need richer accounts that take in more than mere morphological forms; in regard to cognition, we need to admit cognitive processes of abstraction, not solely metaphor, inter-domain likenesses.

I have based the main story on languages I am personally relatively familiar with, the languages of the Kimberley region of north-west Australia, where there is reasonable empirical support for the claim that COM markers can extend into the temporal domain. In order to bolster the case and show that it is not some quirk of the languages of that region, I examined a small number of other Australian languages, and found additional potential support for the proposals. A genuine difficulty is that the elements we are dealing with are typically short, often monosyllabic, and it becomes impossible (in the absence of sound historical-comparative investigation) to make a convincing case for relatedness - all we can do is say that there are suggestive possibilities that lend themselves to interpretation in accordance with my proposals. An example is the present tense suffix in Diyari (see example (2)), which is potentially cognate with the widespread comitative $-y i \sim-t h i$, though with such forms anything is possible!

In some respects the findings may well seem unremarkable. After all, it is well known that have auxiliaries in English and other Indo-European languages grammaticalise to aspect markers. So why not their non-verbal counterparts, COM affixes and adpositions? Despite the limitations of the present investigation, the evidence seems to hint that there are differences in the grammaticalisation pathways of the two phenomena. In my opinion, future investigations of grammaticalisation would do well to pay close attention not just to overt forms as such, but also to the type of morpheme they represent as well as to grammatical relations and inherent semantics, and to explore differences in possible outcomes associated with the different sources.

To avoid possible misunderstandings, I wind up the paper with some explicit comments 
about what I am n ot claiming. Most obviously I am not claiming that all verbal tense, mood and aspect markers have sources in nominal comitatives. Nor am I claiming that a language cannot borrow verbal morphology: that somehow this material is resistant to borrowing, and must result from grammaticalisation processes operating on borrowable nominal morphology. What I have suggested is that if a language borrows a comitative morpheme, it is borrowed as the most concrete comitative, and that this may later undergo grammaticalisation. ${ }^{14}$ There is no suggestion that a language could not borrow the comitative of a neighbour as a dual marker, or even as a progressive marker, provided that those uses of the comitative are attested in the source language. The Bunuba iterative marker might be a case in point, a verbal aspect marker that was borrowed as such; although it can perhaps be traced back historically to a comitative in proto-Worrorran, it need never have been a comitative in any precursor to Bunuba. (Though in this case there is evidence from its close relative Gooniyandi that it was once a comitative.) Furthermore, should a language borrow such a progressive morphemes it is suggested that it will not undergo inverse processes of grammaticalisation, and end up marking an associative relation, or duality, for instance. The grammaticalisation pathway is irreversible.

\section{REFERENCES}

Anderson, John M. (1971), The grammar of case: towards a localist theory, Cambridge: Cambridge University Press.

Anderson, John M. (1973), An essay concerning aspect: some considerations of a general character arising from the Abbé Darrigol's analysis of the Basque verb, The Hague: Mouton.

Beale, Tony (1976), "Biri", in: Dixon. Robert M. W. (ed.) (1976), Grammatical categories in Australian languages, Canberra: Australian Institute of Aboriginal Studies, pp. 266269.

Breen, J. G. (1981), "Margany and Gunya”, in: Dixon, Robert M. W., Barry Blake (eds.) (1981), Handbook of Australian languages, Vol. 2, Canberra: Australian National University Press, pp. 275-393.

Bybee, Joan L., Östen Dahl (1989), "The creation of tense and aspect systems in the languages of the world", Studies in Language, 13 (1989), pp. 51-103.

Capell, Arthur, Howard H. J. Coate (1984), Comparative studies in northern Kimberley languages, Canberra: Pacific Linguistics.

Clendon, Mark (2001), Topics in Worora grammar, PhD thesis, Adelaide University.

Crowley, Terry (1983), “Uradhi”, in: Dixon, Robert M. W., Barry Blake (eds.) (1983), Handbook of Australian languages, Vol. 3, Canberra: Australian National University Press, pp. 307-428.

Dench, Alan, Nicholas Evans (1988), "Multiple case-marking in Australian languages", Australian Journal of Linguistics, 8 (1988), pp. 1-47.

Dixon, Robert M. W. (1980), The languages of Australia. Cambridge: Cambridge University Press.

Dixon, Robert M. W. (2002), Australian languages: their nature and development, Cambridge: Cambridge University Press. 
Evans, Nicholas (1985), Kayardild: the language of the Bentinck Islanders of north-west Queensland, PhD thesis, Australian National University.

Goddard, Cliff (1985), A grammar of Yankunytjatjara. Alice Springs: Institute for Aboriginal Development.

Heine, Bernd (1997a), Cognitive foundations of grammar. New York: Oxford University Press.

Heine, Bernd (1997b), Possession: cognitive sources, forces, and grammaticalization. Cambridge: Cambridge University Press.

Heine, Bernd, Ulrike Claudi, Friederike Hünnemeyer (1991), Grammaticalization: a conceptual framework. Chicago: University of Chicago Press.

Hudson, Joyce (1976), "Walmadjari", in: Dixon, Robert M. W. (ed.) (1976), Grammatical categories in Australian languages, Canberra: Australian Institute of Aboriginal Studies, pp. 205-208.

Ikegami, Yoshihiko (1984), "How universal is a localist hypothesis? A linguistic contribution to the study of 'semantic styles' of language", in: Fawcett, Robin P., Michael A. K. Halliday, Sydney M. Lamb, Adam Makkai (eds.) (1984), The semiotics of culture and language, London, Dover, N.H.: Frances Pinter, pp. 49-79.

Jackendoff, Ray (1990), Semantic structures. Cambridge/Mass., London: MIT Press.

Jackendoff, Ray (1996), "The architecture of the linguistic-spatial interface", in: Bloom, Paul, Mary A. Peterson, Lynn Nadel, Merrill F. Garrett (eds.) (1996), Language and space, Cambridge/Mass.: MIT Press, pp. 1-30.

Keen, Sandra (1983), "Yukulta”, in: Dixon, Robert M. W., Barry Blake (eds.) (1983), Handbook of Australian languages, Vol. 3, Canberra: Australian National University Press, pp. 191-304.

Knight, Emily, in preparation, A grammar of Bunuba, PhD thesis, University of New England.

Lakoff, George Mark Johnson (1980), Metaphors we live by, Chicago, London: University of Chicago Press.

Lyons, John (1968), Introduction to theoretical linguistics, Cambridge: Cambridge University Press.

Lyons, John (1977), Semantics, Vol. 2, Cambridge: Cambridge University Press.

McGregor, William B. (1993), Gunin/Kwini, München, Newcastle: Lincom Europa.

McGregor, William B. (1994), Review of Paul J. Hopper, Elizabeth Closs Traugott (1993), Grammaticalization, Cambridge: Cambridge University Press, Functions of Language, 1 (1994), pp. 304-307.

McGregor, William B. (1997), "The story of -ngany in Nyulnyulan languages", Paper presented to First International Workshop on Australian Linguistics, University of Melbourne.

McGregor, William B. (1998a), "Applicative constructions in Warrwa", in: Siewierska, Anna, Jae Jong Song (eds.) (1998), Case, typology, and grammar: in honour of Barry J. Blake, Amsterdam: John Benjamins, pp. 171-199.

McGregor, William B. (1998b), "The Gooniyandi suffix -wa", in: Caron, Bernard (ed.) (1998), Proceedings of the Sixteenth International Congress of Linguists, Paris: Elsevier, Paper No. 0201. 
McGregor, William B. (2002), Verb classification in Australian languages. Berlin, New York: Mouton de Gruyter.

McKay, Graham (2000), "Ndjébbana", in: Dixon, Robert M. W., Barry Blake (eds.) (2000), The handbook of Australian languages, Vol. 5, Melbourne: Oxford University Press Australia, pp. 154-354.

Rumsey, Alan L. (1982), An intra-sentence grammar of Ungarinjin, North-western Australia, Canberra: Pacific Linguistics.

Rumsey, Alan L. (2000), "Bunuba”, in: Dixon, Robert M. W., Barry Blake (eds.) (2000), The handbook of Australian languages, Vol. 5, Melbourne: Oxford University Press Australia, pp. 34-152.

Saulwick, Adam (1996), To have and to hold: the semantics of the proprietive case in Australian languages, BA (Hons) thesis, University of Melbourne.

Schultze-Berndt, Eva (2000), Simple and complex verbs in Jaminjung: a study of event categorisation in an Australian language, PhD thesis, Catholic University of Nijmegen.

Smith, Ian, Steve Johnson (2000), "Kugu Nganhcara", in: Dixon, Robert M. W., Barry Blake (eds.) (2000), The handbook of Australian languages, Vol. 5, Melbourne: Oxford University Press Australia, pp. 355-489.

Stokes, Bronwyn (1982), A description of Nyigina: a language of the West Kimberley, Western Australia, PhD thesis, Australian National University.

Stokes, Bronwyn, William B. McGregor, forthcoming, "Classification and subclassification of the Nyulnyulan languages", in: Evans, Nicholas (ed.), Comparative studies in non-Pama-Nyungan, Canberra: Pacific Linguistics.

Traugott, Elizabeth Closs (1978), "On the expression of spatio-temporal relations in language", in: Greenberg, Joseph H. (ed.) (1978), Universals of human language, Vol. 3, Word structure, Stanford: Stanford University Press, pp. 369-400.

Tsunoda, Tasaku (1976), "Warungu“, in: Dixon, Robert M. W. (ed.) (1976), Grammatical categories in Australian languages, Canberra: Australian Institute of Aboriginal Studies, pp. 214-225.

Vászolyi, Eric (1976), "Wunambal", in: Dixon, Robert M. W. (ed.) (1976), Grammatical categories in Australian languages, Canberra: Australian Institute of Aboriginal Studies, pp. 629-646.

Wilkins, David (1989), Mparntwe Arrernte (Aranda): studies in the structure and semantics of grammar, PhD thesis, Australian National University.

Wilson, Stephen (1999), Coverbs and complex predicates in Wagiman. Stanford: CSLI Publications.

Yallop, Colin (1982), Australian Aboriginal languages. London: Andre Deutsch. 


\section{NOTES}

1 This is a revised version of my presentation to the symposium "Tid i Sprog", Statsbiblioteket, $29^{\text {th }}$ November 2002. I thank the audience for their questions, which have caused me to refine my formulations and conclusions somewhat.

2 The paper I had originally intended for the "Tid i Sprog" conference was addressed primarily to the first issue, and proposed that an alternative important source of temporal grammar lay in events: that historical processes of grammaticalisation could be found in some Australian languages involving verbs serving as the historical source of temporal morphemes. This is not a new observation, and has been remarked by numerous grammarians, Australianist and other. In fact, some of the classical situations adduced in support of localism involve verbal sources, and turn out on close examination not to support the primacy of spatial relations. A case in point is the proposal that events of change of state are construed in terms of change of position via localist metaphor (e.g. Lyons 1977: 720). But change of position is motion in space, obviously an event, and one could equally argue that the event is more fundamental than the spatial relation, and that ultimately both spatial and temporal domains are construed through motion (see also Ikegami 1984) The 'be at' source for progressives, likewise, could be argued to be fundamentally based on the stative event rather than the locative relation. Although I am convinced that there is something to this hypothesis, I was concerned about drawing cognitive conclusions (the fifth concern above) on the same sort of flimsy evidence from linguistic form as proponents of localism accept.

3 These morphemes (at least some of them) have also been called "proprietives". In general I prefer the term "comitative" because it focuses on what I consider to be the critical feature, the notion of 'with-ness'; the term "proprietive", by contrast, suggests - wrongly in most instances - that the notion of property or ownership is fundamental.

4 The following abbreviations are used in this paper: $\mathrm{ABL}-$ ablative; $\mathrm{ABS}-$ absolutive; ACC - accusative; ALL - allative; ASSOC - associative; AUG - augmented; CA — catalyst; COM - comitative; CONT - continuative, continuous; CTP - contemporary; DAT - dative; DEF — definite; DU — dual; ERG - ergative; EXC — exclusive; EXT — extent; FREQ — frequentative; FUT - future; GEN — genitive; INDEF — indefinite; INDIC — indicative; INST — instrumental; INT — intensive; INTENT — intentive; IRR — irrealis; IT — iterative; IV — inflecting verb; LOC — locative; min — minimal; NEG — negative; NOM — nominative; OBL — oblique; PA — past; PASS - (anti)passive; PC - past continuous; pl - plural; POS - possessive; POT - potential; PRES - present; PROG — progressive; PROX — proximal; PURP — purposive; RE — realis; REF - contextual deictic; REM - remote; sg — singular; UV - uninflecting verb; V — verb; and VCOMP - verbal complementiser. 1, 2, and 3 indicate the three person categories; subscripted letters indicate noun classes; > acting on; and inflecting verbs are cited in capitals.

5 Dixon (1980: 317) traces these allomorphs back to proto-Australian.

6 Most languages of northern Australia have two lexical classes of verb, which I refer to as inflecting verbs and uninflecting verbs (UVs), according to their ability to take verbal inflections. UVs allow little in the way of morphological modification, and normally occur in syntagm with IVs, in what are usually referred to as compound verb constructions. For fuller treatment see e.g. McGregor (2002), Schultze-Berndt (2000), and Wilson (1999).

7 The description of Knight (in preparation) seems to suggest that only the habitual sense is available, though examples such as (6) would seem to indicate otherwise.

8 Nearby Gunun/Kwini has a nominal postposition that is most likely a cognate comitative marker (McGregor 1993: 39 wrongly analyses it as a purposive). It is not, however attested as a UV affix, although the suffix -me, referred to in McGregor (1993: 49) as a distributive marker, is possibly an allomorph conditioned by a final nasal in the UV.

9 In one of the languages cited by Saulwick, Kala Lagaw Ya, the COM marker seems to be exclusively associated with nominals, and for this reason is ignored here.

10 Another plausible cognate is the enclitic or suffix -nyali, that is widespread in Kimberley languages, with a range of meanings including 'again', 'also', 'too', and so on. It occurs as a free word 'again' in Worrorra.

11 According to Capell/Coate (1984: 208), in Worrorra the CONT followed by - $d a$ expresses customary aspect. 
12 The change in quality of the first vowel could be due to the following palatal consonant.

13 Notice that this proposal conflicts with Rumsey's scenario for the Bunuba progressive cited above (Rumsey 2000: 97), which invokes movement from quality to time.

14 Is there any reason why a language would not borrow a comitative in the full range of uses, nominal and verbal? I have no argument against such a scenario given that (i) the source language shows all of the uses, and (ii) that the borrowing language does not have a separate comitative of its own. The existence of a native comitative in the borrowing language would, I suspect, induce a borrowed comitative to enter in at the most concrete part of the semantic domain, where it would perhaps be most necessary to draw a semantic distinction between association (of a vague type) and accompaniment. 